\title{
Cuisine and Identity in Contemporary Japan
}

\section{Citation}

Bestor, Theodore C. and Victoria Lyon Bestor. 2011. Cuisine and identity in contemporary Japan. Education about Asia 16(3): 13-18.

\section{Permanent link}

http://nrs.harvard.edu/urn-3:HUL.InstRepos:11639566

\section{Terms of Use}

This article was downloaded from Harvard University's DASH repository, and is made available under the terms and conditions applicable to Other Posted Material, as set forth at http:// nrs.harvard.edu/urn-3:HUL.InstRepos:dash.current.terms-of-use\#LAA

\section{Share Your Story}

The Harvard community has made this article openly available.

Please share how this access benefits you. Submit a story.

Accessibility 


\section{Guisine and Identity in Contemporary Japan \\ By Theodore C. Bestor and Victoria Lyon Bestor}

Editor's Note: Portions of this article appeared in Victoria Bestor and Theodore C. Bestor, with Akiko Yamagata, eds., Routledge Handbook of Japanese Culture and Society (New York: Routledge Publishers, 2011).

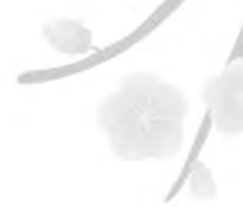

$\mathbf{F}$ ood is all around us, yet remarkably elusive for something seemingly so concrete and mundane. People grow it, buy it, prepare it, eat it, savor it (or not) every day, everywhere, often without much thought about food's significance in larger social, cultural, or historical schemes. Food is profoundly embedded in these frameworks, and shoku bunka (food culture) is a key concept for understanding the day-to-day foodways of Japanese society. Today in Japan, foodstuffs and cuisine attract constant attention. Culinary choices and their connections to lifestyle and identity are trumpeted in advertising, in the mass media, and in restaurants and supermarkets across the country.

Culinary choices, lifestyles, and "distinction" - the linkages between aesthetic taste and economic class standing, between social power and cultural prestige-are tightly packaged in contemporary Japan. Japan’s modern relationship with itself and the world-the juxtaposition of Japan's self-constructed sense of cultural uniqueness and its simultaneous, almost constant incorporation and innovation of things foreignis clearly visible through food and foodways.

\section{Imagining Japanese Cuisine}

Cuisine is a product of cultural imagination and is thought to include the range of practices and preferences that are shared broadly across the members of a society as they prepare and partake of food. This culinary imagination reflects, therefore, a loose agreement on a common and sustained template of cuisine as something definable and distinctive, something with more-or-less known qualities and boundaries.

In the case of Japan, this self-defined (or self-appreciated) template includes a key element: fresh or raw ingredients. Most cultures frame their ideas about food culture around concepts such as the bounty of the land and the changing seasons, the natural world. Food is nature transformed by culture, and culture is a powerful force with which to fasten symbolism and meaning to the mundane facts of life, such as cooking and eating. In the following sections, we sketch some of the most significant aspects of cultural symbolism, ideas about tradition, and other aspects of Japanese food culture, belief, and food lore seenas they so often are-as stable and relatively unchanging.

One of the most central of culinary things in Japan, in both practical and symbolic terms, is rice. Rice cultivation is a hallmark of East and Southeast Asian agriculture, where seasonal monsoons provide the water necessary for elaborate irrigation systems. Japanese civilization developed around rice cultivation, made indigenous through the myths and rituals of Shinto religion that are closely tied to rice (as well as to the gods who gave mythological rise to the Japanese imperial line). Many Shinto rituals are linked to the calendar of rice production, and even the present-day emperor annually transplants rice seedlings in a paddy inside the Imperial Palace at the center of

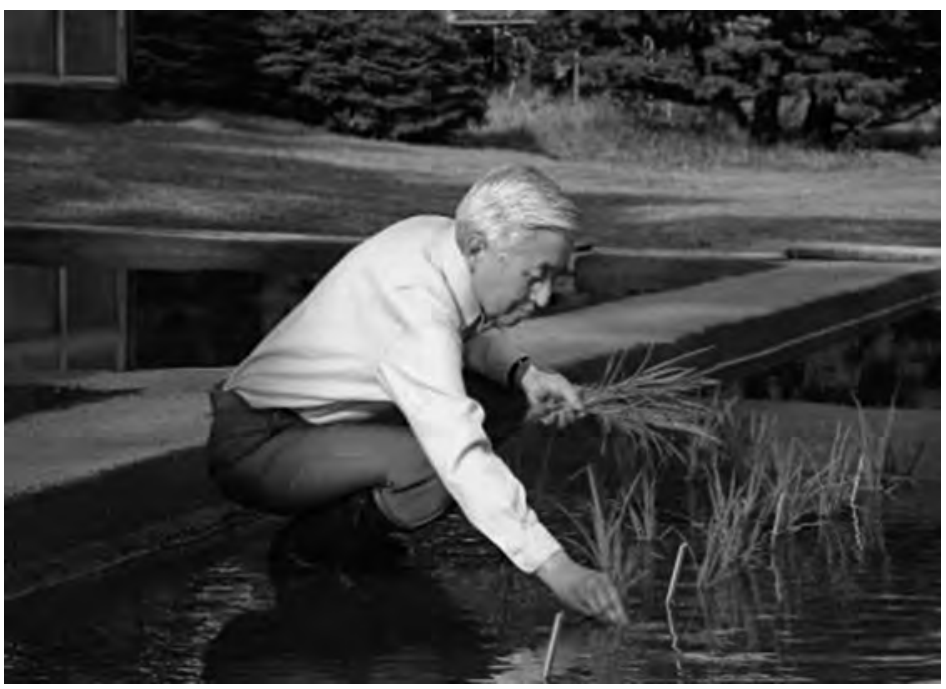

May 2011, Heisei Emperor planting rice in the rice paddies of the Imperial Palace. Source: http://tiny.cc/bhq96. Tokyo.

The emperor celebrates not only the ritual event of rice planting but also the flow of the agricultural year: cuisine is constructed across calendars that reflect many dimensions, including concepts of seasonality. Even in a globalized food system that delivers products from around the world without much regard for month of the year, Japanese food culture places great emphasis on seasons. Seasonality defines varieties of seafood, not just by availability and quality, but also by their essential characteristics. That is, fish of the same species may be known by different names depending on the time of year they are caught, their size, their maturity, or the location where they are taken (all of which may be closely interrelated).

\section{Even in a globalized food}

\section{system that delivers}

products from around

the world without much

regard for month of the

year, Japanese food

culture places great

emphasis on seasons. 


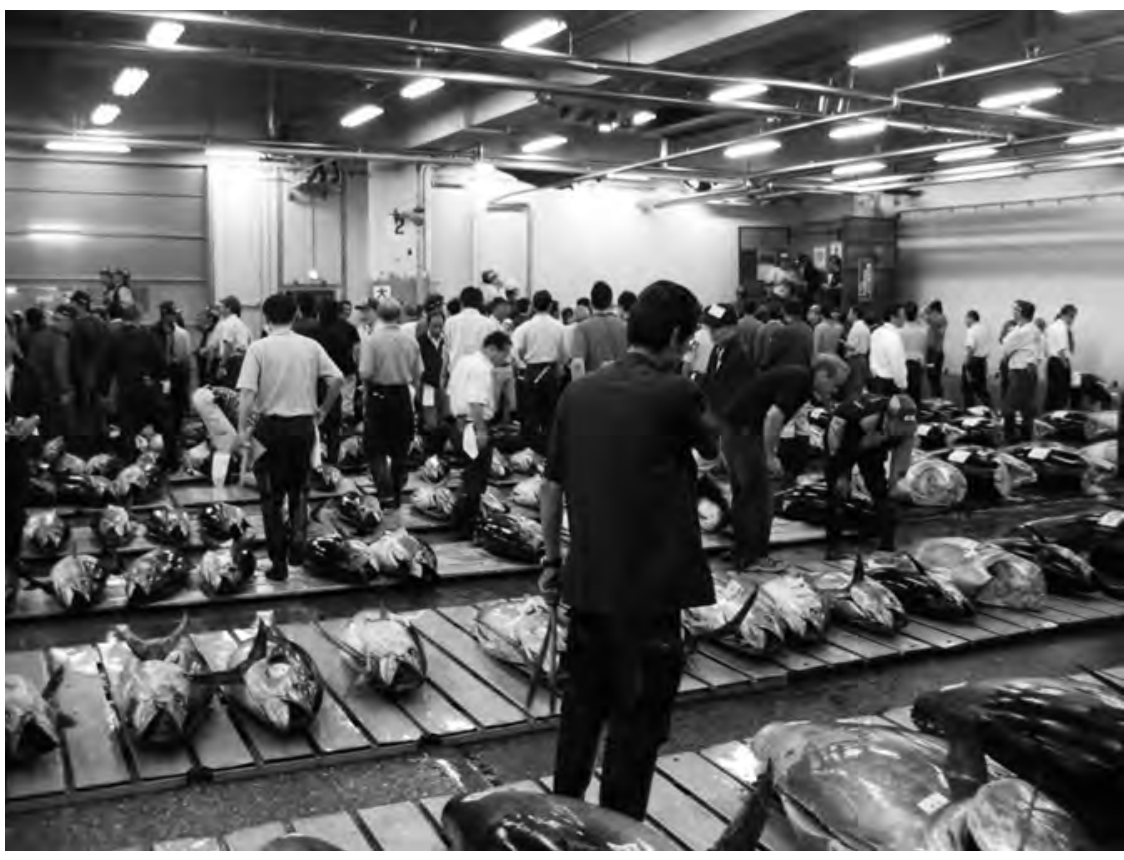

Tuna auction at Tsukiji fish market in Tokyo. Source: http://tiny.cc/vbgwi.
This degree of concern over hyper-seasonality is most pronounced in top-end restaurants and among professional chefs, food critics, and travel writers. Culinary seasonality is complemented by many other traditional contexts of Japanese culture that mark divisions of the year through such things as wellknown poetic allusions, customary greetings, or color combinations and patterns (of kimono, for example) that are appropriate to and emblematic of the rapidly passing seasons.

Closely related to notions of seasons are so-called hatsumono (first things), the first products of a season: the first bonito; the first apples from Aomori; the first tuna of the year to be auctioned at Tsukiji. ${ }^{1}$ Stores, restaurant menus, and the mass media trumpet the arrival of the "first" as a harbinger of the season. For true connoisseurs of Japanese cuisine, the first products (of whatever kind) may be awaited with as much excitement as wine-lovers (in Tokyo as much as in Paris) muster for the arrival of a new vintage from an exalted vintner.

Culinary calendars also mark events, holidays, and festivities that occasion particular kinds of foods. The celebration of the New Year has many food associations, ranging from the simple act of eating especially long noodles on New Year's Eve to ensure long life and prosperity to the extremely elaborate banquets for the holiday itself. Many osechi (New Year's foods) have auspicious meanings based on color combinations (lobsters and crabs, for example, combine celebratory red and white) or double meanings (the word "tai" for sea bream also means "congratulations"). Osechi is served in elaborate sets of stacking and nesting lacquered boxes and trays, and the food is prepared in advance, the folklore being that housewives should be spared from cooking during the holiday. In the past, cooking fires were supposed to be extinguished during the first days of the New Year.

Other times of the year also have food associations. In mid to late summer, for example, food lore instructs one to eat unagi (broiled eel) to fortify the body against the heat on very specific dates determined by traditional almanacs. Other celebratory dishes are not tied to specific holidays or seasons but are consumed throughout the year, such as the auspiciously red-and-white combination of sekihan (red beans and sticky rice) that is common at festivals, family celebrations, weddings, and other occasions. Twice each year there are seasons for extensive gift giving-ochügen in July and oseibo in December-which prominently include many fancy and ordinary foodstuffs, heavily promoted by manufacturers, department stores, supermarkets, and specialty food purveyors.

\section{Domesticating Foreign Cuisines}

The culinary imagination of a unified and stable Japanese cuisine does not exist in a vacuum but is formed in contrast to the many things Japanese eat that are not considered "Japanese." Of course, much of the traditional diet of the country fundamentally resembles that of environmentally similar regions of Asia that were part of the extended zone of Chinese civilization. Many of the central foodstuffs of Japanese cuisine (e.g., rice, soybeans, tea, sesame oil); methods of cultivation or preparation (irrigating rice paddies, fermenting soy beans into soy sauce, making tofu or noodles, etc.); and styles of utensils, cooking techniques, and flavorings come from the Asian mainland and mark significant parallels with the various national cuisines of East and Southeast Asia.

The identification of dishes as part of a distinctive "traditional" Japanese cuisine does not imply historical stasis. Like all other aspects of "tradition," food culture constantly evolves. The exposure of Japanese foodways to foreign, and in particular Western, influences that fundamentally changed the Japanese diet took place in several distinct historical periods since the medieval period. In the sixteenth century, Japan had its first contact with Western sea powers, primarily the Portuguese and the Dutch. Drawing distinctions between Japanese cuisine and other foodways undoubtedly accelerated as Western contact brought not only exposure to Europe but also to the many other regions of the world already enmeshed in European trading empires, including South and Southeast Asia (with an abundance of spices unfamiliar to Japan).

The so-called "Columbian Exchange"- the transfers of peoples, plants, animals, and diseases in both directions between the Old and New Worlds following the voyages of Columbus in 1492-rapidly affected East Asia. Foodstuffs from the New World that made their way to Japan during the sixteenth century included sweet potatoes, potatoes, and capsicum (red) peppers (and a non-food item: tobacco). Japanese foodways were also affected by the cooking of the European explorers, missionaries, and traders following the 1549 arrival of the Jesuit priest Francis Xavier in Nagasaki. Tempura is generally regarded as a culinary innovation stimulated by Portuguese influence in Kyūshū, and many new foodstuffs arrived, either directly 
from European contact or indirectly from other Southeast and East Asian countries. European words (or adaptations of them) entered the Japanese language as well: $k \bar{o} h \bar{\imath}$ (coffee), tempura (from a Portuguese term), piripiri (hot, spicy, from a Swahili term for red peppers brought from the New World to Iberia, then to East Africa and on to East Asia by Portuguese traders), kasutera (an Iberian pound cake), and pan (bread, from Portugal).

From the seventeenth through the nineteenth centuries, Japan maintained self-imposed isolation. The culinary influences occasioned by sixteenth-century contacts with the Portuguese and the Dutch were largely confined to the new crops (including New World crops) that took root in Japan; the level of actual trade between Japan and the rest of the world was modest, and foodstuffs played little part in it.

During the two and a half centuries of Tokugawa rule, Japan was at peace. Despite periodic massive famines, agriculture was generally productive, and many innovations expanded the range of rice cultivation. Despite the political unification of the country, Tokugawa policy restricted travel in many ways, and because contacts among different regions were limited, local foodways and specialties were strongly maintained. Official travel to and from Edo (as Tokyo was known until the 1870s), however, was mandatory for local lords and higher-ranking samurai from each of the fiefs, so Edo became a melting pot into which metropolitan tastes and flavors-in literature, fashion, art, politics, and cuisine-were created and disseminated to the provinces with the comings and goings of the elite. Guidebooks provided detailed descriptions (and rankings) of the culinary delights of the capital, and famous restaurants were often depicted in woodblock prints (the souvenir postcard of the day).
Kikkoman, the soy sauce

company, dates to several

families active in the trade

near Edo in the mid-seven-

teenth century; Mizkan,

the producer of rice vinegar,

began in 1804 in a port city

near Nagoya, astride the

trade routes linking Edo

and Osaka.

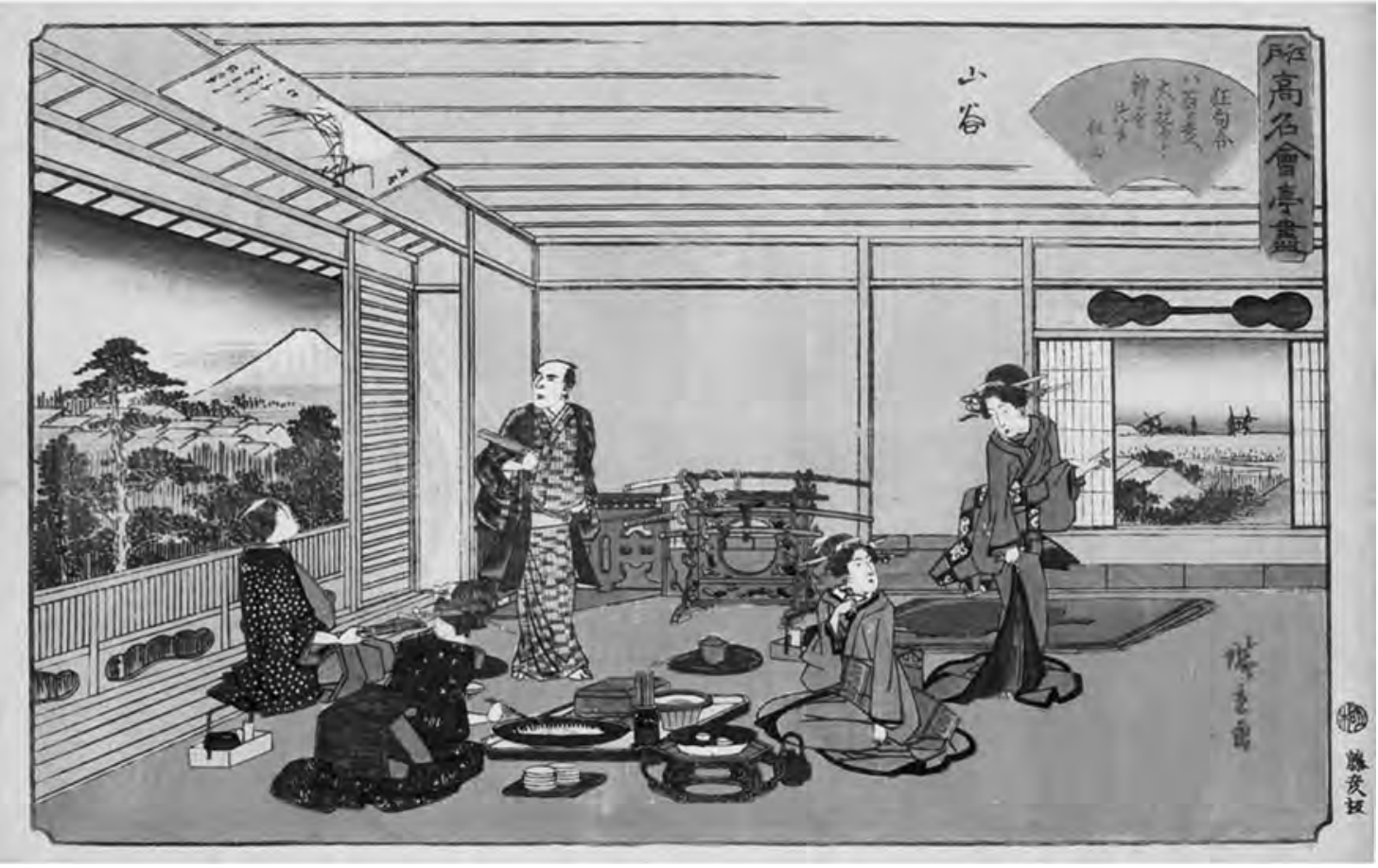

Woodblock print by Utagawa Hiroshige (1797-1858). “Yaozen Restaurant at Sanya” from Grand Series of Famous Tea Houses of Edo (ca. 1839-1842). Japan, Edo period. Source: Honolulu Academy of Arts website at http://tiny.cc/6fxss.

The peace and prosperity of the period also enabled the development of regional food processing industries that had extended geographic reach. Sake brewers, the producers of soy sauce, and the manufacturers of rice vinegar, for example, in some cases became regional rather than merely local. A number of prominent food companies active today can trace their origins to the proto-industrial production of the Tokugawa period; Kikkoman, the soy sauce company, dates to several families active in the trade near Edo in the mid-seventeenth century; Mizkan, the producer of rice vinegar, began in 1804 in a port city near Nagoya, astride the trade routes linking Edo and Osaka. And the dietary needs of large cities like Edo and Osaka were met by local agricultural production, as well as large-scale interregional trade in basic foodstuffs such as the Osaka-to-Edo rice trade and the Hokkaidō-to-Osaka fish trade.

Following the "opening" of Japan by the American naval officer Commodore Matthew Perry in 1853-54, Japan experienced an accelerating flood of foreign influences across every aspect of life, including the culinary. The Meiji period (1868-1912) saw a flood of imported products, and the upper and uppermiddle classes especially experimented with new tastes and menus, both at home and in restaurants. In the 1870s, there was a boom in consumption of beef, emulating European tastes for red meat (officially 


\section{Western foodstuffs became}

commonplace in many

urban diets-toasted Gread

with mixed green salad

and coffee for breakfast, curry rice for lunch,

perhaps spaghetti

for dinner.

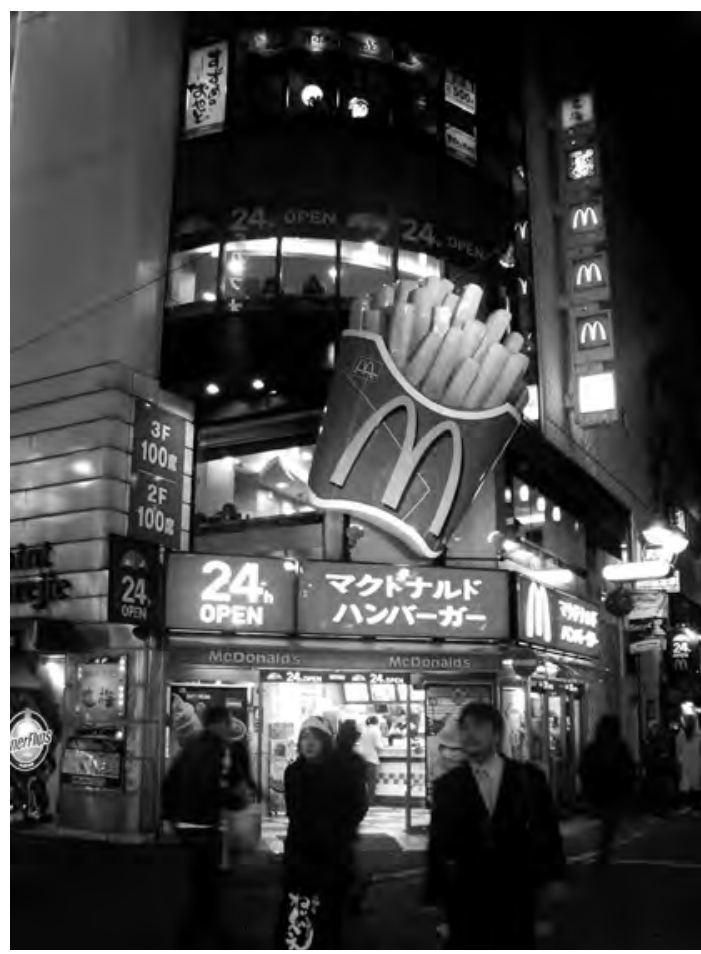

One of over 3,500 McDonald's restaurants in Japan. Source: http://tiny.cc/ig5hy. long-forbidden by Buddhist proscriptions) in the form of a traditional kind of dish simmered with soy sauce-a dish now internationally known as sukiyaki. Particularly in Tokyo and the treaty ports where Westerners were allowed to settle (such as Yokohama and Kobe), restaurants provided introductions to European cuisines for urban sophisticates. Wax models of food were first displayed to visually explain foreign dishes to diners unfamiliar with them; such models (in plastic) remain very common in restaurant displays today.

The food purveyor Meidiya, established in 1885 (named for the Meiji era, retaining an archaic English transliteration), is an example of the companies that developed to meet the demand of imported Western foodstuffs. Businesses and restaurants helped promote the boom in Western-style consumption for Meiji-era elites and led the way for other foreign and domestic specialty stores. The early twentieth century saw the development of department stores as centerpieces of urban modernity. By the 1920s, department stores in large urban centers had assumed premier roles in defining middle and upper-middle class consumption, including foodstuffs. Department stores developed food floors (generally the basement) that featured the finest products, both domestic and foreign. Such department store food halls continue to be arbiters of high-level cuisine.

In the twentieth century, Japan's extensive colonial empire throughout East and Southeast Asia also influenced the development of Japanese domestic food life. Dishes and tastes from elsewhere in Asia became standard components of Japanese consumption (e.g., Chinese restaurants, the introduction of spicy kimchee from Korea, or the wide popularity of ramen noodle soup from north China).

An extremely important aspect of Japan's culinary transformation was the impact of the Japanese military on dietary norms, as food anthropologist Katarzyna Cwiertka has argued. ${ }^{2}$ From the creation of a mass conscript army in 1873 through Japan's defeat in 1945, the Japanese military was one of the major institutions shaping national life. With a huge conscript base, the military faced the challenge of creating a nutritionally solid military diet that had to be relatively easy to prepare in standardized ways for large numbers of people. Since the promotion of national unity was also of great importance, aspects of Japanese cuisine that traditionally reflected sharp regional or class differences needed to be avoided. Perhaps surprisingly, military nutritionists adopted many dishes from European countries to become standards in the military diet, including curry rice, pasta dishes, soups, and stews. The British naval diet, for example, with its relatively large portions of beef, was seen as a model for building the stamina of Japanese soldiers and sailors.

After Japan's defeat, the Allied (primarily American) Occupation of Japan launched another wave of culinary innovation and adaptation. Some Japanese foods were adapted to the tastes of the occupiers. (Large amounts of meat cooked on a steel griddle became the now-standard dish teppanyaki.) American forces brought with them a diet rich in dairy products, meat, and animal fats of all kinds; this had a major impact on Japanese food consumption and tastes during the postwar period.

The war and its immediate aftermath brought near starvation to millions and permanently severed Japan from its previous colonial sources of food supply. The postwar economic recovery of the 1950s and 1960s-the so-called economic miracle-focused primarily on the development of heavy industry and export industries but also created entirely new lifestyles for many Japanese. From the 1950s onward, the urban population exploded, and rural areas (and their foodways) declined; smaller nuclear families became the norm, and shopping, cooking, and eating habits changed. Large-scale food manufacturers took over production in many segments of the food industry, and local or regional producers suffered. Increasing proportions of the food consumed in Japan were imports, and Western foodstuffs became commonplace in many urban diets-toasted bread with mixed green salad and coffee for breakfast, curry rice for lunch, perhaps spaghetti for dinner.

In the 1970s, Japan emerged from its high-speed growth years as a full-fledged economic powerhouse, with a prosperous urban middle class that looked to Europe and the US for models of consumption. The 1970s and 1980s were a period of hyper-consumption, and Western-inflected food fads flourished at both the high end of fine European imports and on the mass level. (The first McDonald's in Japan opened in the Ginza district of Tokyo in 1971; it was an instant success.) The last quarter of the twentieth century and the first decade of the twenty-first have seen a commercial transformation of the world of food in many ways. Japanese imports of food from overseas have continued to soar. Vast empires of fast food chains saturate most urban areas. Home dining and food preparation account for an ever-smaller proportion of food-related expenditures. Supermarkets and Konbini (convenience stores) have driven out of business many of the small specialized local food stores that previously dotted the urban landscape, and the stock-in-trade of konbini are highly processed prepared foods that are themselves transforming the nutritional standards of the Japanese diet. 
At the same time, the level of interest in food at the high end continues to sustain a gourmet boom focused on the finest ingredients and styles of preparation, whether domestic or foreign. On the domestic front, what we have called the "gentrification of taste" has resulted in a revival of regional dishes, local producers, or styles of preparation that had been fading away as old fashioned. These are now touted for their authenticity and often lauded for sustainability, local roots, and other "slow food" characteristics.

One can look at changes in the Japanese diet since the nineteenth century as incremental innovations and stylistic shifts along a chronological sequence. Another way to think about Japanese consumers' access to a vast array of both domestic and cosmopolitan foods is as a consequence of the transformations in the Japanese diet brought about by "the industrialization of food." As part of a new global food system, this entails a macroscopic and multifaceted set of transformations in which the entire character of a society's sustenanceselections of food resources, methods of production and processing, techniques of distribution, daily rhythms of eating, and the creation of entirely new foodstuffs-is adapted to and shaped by industrial, capital-intensive production.

Clearly, from the late nineteenth century onward (and in some cases from much earlier), Japanese foodways have been increasingly industrialized. The nineteenth- and twentieth-century transformation of Japanese foodstuffs reflected the introduction of new foods from the West and its colonial empires, new techniques and technologies for processing food, and new modes of cooking and dining. Industrialized food production promoted both the standardization of foodstuffs and the mass marketing of products such as canned fish and meat products, vegetables, and fruits that became common commodities in the early decades of the twentieth century.

Typically, industrialization of food changes the repertory of goods available to consumers, increasingly substituting highly standardized, processed, and manufactured foodstuffs for widely varied, locally produced, raw, and semi-processed ones. This affects consumers, of course, but the transformations are fundamentally propelled by changes in the economic, po-

\section{Bentō: Portable Meals}

One of the most common ways that Japanese consume food outside the home is bentō (sometimes more formally called o-bentō, the "o" being an honorific). Bentō are box lunches, carefully packed into compartmentalized containers, with small portions of cooked meat, poultry, or fish; one or two vegetable dishes; and always a good serving of boiled rice.

In the past, bentō were served in elaborate lacquered boxes; today the lacquer is reserved for special occasions. Workers and students carry homemade bentō in plastic or metal containers on their daily commutes or buy bentō in disposable packages from retailers in sta-

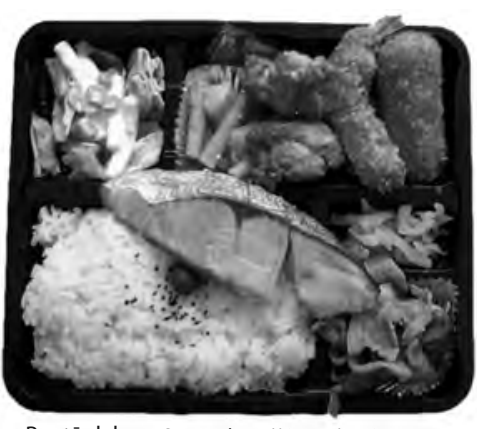
Bentō deluxe. Source: http://tiny.cc/3u4je. tions, at specialized take-out shops, or at the ubiquitous konbini.

Bentō are available everywhere and are the midday meal for millions of students and workers. Travelers also pick them up as a treat for a journey and may bring bentō home as gifts containing famous local culinary specialties.

Homemakers often lavish enormous amounts of attention on the ingredients and cooking techniques, as well as on the appearance of the bentō itself, which reflects well on her skills. Some go to extraordinary lengths

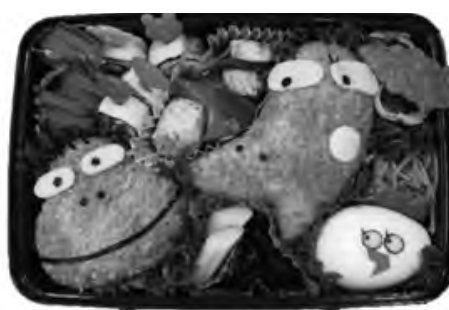

Bentō for children. Source: http://tiny.cc/s7kwj. to craft bentō in the image of cartoon characters and other fanciful scenes (examples of which are easily found on the Internet).

Although some schools allow bentō, many public schools instead serve hot lunches in the classroom. This assures that all students eat equally nutritious meals, social status is not highlighted in the richness or meagerness of food brought from home, and students shoulder responsibility by serving food themselves and cleaning up afterward. - Theodore C. Bestor and Victoria Lyon Bestor

litical, and social institutions that produce, process, and distribute foodstuffs.

Industrialization of food can also define or redefine what is traditional. Many dishes and delicacies now widely regarded as hallmarks of Japanese cuisine are of relatively recent introduction or invention. For example, even the basic form of nigiri-zushi, a thin slice of fish atop a compact oblong block of vinegared ricethe style characteristic of Tokyo's cuisine and now the world's de facto sushi standard-was an innovation of the mid-nineteenth century. Many of its contemporary features, including exquisitely fresh fish rather than various kinds of pickled or salted seafood, only became possible in the twentieth century with the advent of mechanical refrigeration and ice manufacturing. ${ }^{3}$

\section{The Branding of "Cool Japan"}

The prestige associated with being relatively omnivorous and attuned to connoisseurship exists in Japan as it does in many other prosperous middle class societies. To discern and savor many styles of Japanese cuisine, as well as to appreciate the finer points of high-status foreign foods, is to secure a claim as a sophisticated Japanese and a cosmopolitan "citizen-of-the-globe." This juxtaposition of the local and the global, the domestic and the transnational, has been an important aspect of larger Japanese identity politics since the high-speed economic growth era of the 1960s.

The culinary dimensions of social distinction are also, importantly, products of the vast media attention paid to food in all its forms, which has exploded over the past generation. Commentators on cultural 
Internationally, for both foreign observers and food tourists, Japanese cuisine is part of the enticement of Japan's "soft power."

\section{OISHINBO}

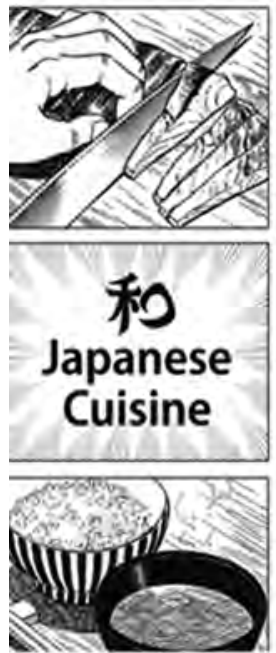

Cover of Oishinbo, Vol. 1.

Source: The VizManga website at http://www.vizmanga.com/reader/393. production often use the term "culture industry" as shorthand to refer to the complex influences and connections that, in industrial capitalist societies, link creators, the content or meanings of the goods or services they create, and the tastes and preferences of those who receive or consume them (creation and production: content and distribution: reception and consumption). Many argue that industry is the prime mover; others argue that the linkages are more fluid and multidirectional and that consumer tastes and preferences (and many social and cultural trends external to industry) shape industry as much as vice versa. Typically, those who write about culture industries focus on mass popular culture and its many mediamusic, film, television, magazines, comics, digital games, and fashion-but it is not far-fetched to think of food culture in similar terms: as an extremely complex system of culinary production, a vast marketing and distribution system, selling items that take shape in many symbolic and social ways, promoted by celebrity chefs, supported by extensive advertising and the doting coverage of mass communication outlets devoted to culinary matters, and presented to consumers whose choices are shaped both by media coverage and by individual impulses for self-fulfillment and social standing-distinction-expressed in culinary fashion. Of course, some of this "food culture industry" is quite specifically media-based-the entertainment value of food as expressed in movies like Itami Jūzōs noodle farce, Tampopo; in the televised fantasy food competitions of Iron Chef; or in the manga series Oishinbo by Kariya Tetsu and Hanasaki Akira, about an investigative reporter engaged in a never-ending quest for culinary authenticity and connoisseurship.

In broader terms, Japanese foodways have become a focus of contemporary discussions among journalists, business leaders, diplomats, and other government officials about "Cool Japan" or "Japan's Gross National Cool," a term coined by the American journalist Douglas McGray. "Cool Japan" is the product of Japan's so-called "content industries" — such as anime, manga, video games, fashion, music, Hello Kitty, and, yes, cuisine - that have generated highly popular (and highly profitable) markets for things Japanese outside of Japan, all the more noteworthy during the past couple of decades in which the Japanese economy as a whole has only stuttered along. The "content industries" (or culture industries) are the beacons of "Cool Japan" and are officially promoted by Japan's Ministry of Foreign Affairs. Domestically, Japanese cuisine is very well branded as a cultural product - an icon of national cultural identity. Internationally, for both foreign observers and food tourists, Japanese cuisine is part of the enticement of Japan's "soft power" (the ability to project attractive cultural influence without international coercion). Clearly "soft power" works! A 2008 Japanese government survey revealed that the leading reason foreign tourists gave for visiting Japan (64.5 percent) was "to eat Japanese cuisine."

\section{NOTES}

1. Theodore C. Bestor, Tsukiji: The Fish Market at the Center of the World (Berkeley: University of California Press, 2004).

2. Katarzyna J. Cwiertka, Modern Japanese Cuisine: Food, Power, and National Identity (London: Reaktion Books; Chicago: University of Chicago Press, 2007)

3. Theodore C. Bestor, "Kaiten-zushi and Konbini: Japanese Food in the Age of Mechanical Reproduction," in Fast Food/Slow

Food: The Cultural Economy of the Global Food System, ed. Richard Wilk (Lanham, MD: Altamira Press, 2006), 131-144.

4. Douglas McGray, "Japan’s Gross National Cool," Foreign Policy 130 (2002): 44-54.

\section{SUGGESTED READING}

Bestor, Victoria Lyon, and Theodore C. Bestor, with Akiko Yamagata, eds. Routledge Handbook of Japanese Culture and Society. London and New York: Routledge, 2011.

Japan Ministry of Foreign Affairs. Kids Web Japan: Visual Culture, Japanese Box Lunches at http://web-japan.org/kidsweb/ virtual/bento/.

Rath, Eric C., and Stephanie Assman, eds. Japanese Foodways, Past and Present. Urbana: University of Illinois Press, 2010. Sand, Jordan. “A Short History of MSG: Good Science, Bad Science, and Taste Cultures." Gastronomica 5 no. 4 (2005): 38-49.

VICTORIA LYON BESTOR directs the North American Coordinating Council on Japanese Library Resources (NCC) which creates access services to Japanese print and digital resources and advocates for the needs of library users, especially those at smaller institutions. She is an Associate of Harvard's Reischauer Institute of Japanese Studies, co-editor of the Routledge Handbook on Japanese Culture and Society, Doing Fieldwork in Japan, and a forthcoming series of modules for the Visualizing Cultures online project looking at twentieth-century transformations of the city of Tokyo. She has written extensively on Rockefeller philanthropy and worked in K-12 outreach at Columbia University, where she was also Associate Director of the Donald Keene Center of Japanese Culture.

THEODORE C. BESTSOR is Reischauer Institute Professor of Social Anthropology at Harvard University, chairs Harvard's anthropology department, and is Vice President (President-elect) of the Association for Asian Studies. His principal research focuses on Tokyo and the interpersonal networks that underpin neighborhoods and markets. He is the author of Tsukiji: Fish Market at the Center of the World and Neighborhood Tokyo. He is currently researching the impact of Japan's March 2011 disaster on food production, consumption, and distribution, and he is one of the founders of Harvard's Digital Archives of Japan's 2011 Disasters (http://www.jdarchive.org) 